\title{
无限怀念毛主席 无限热爱华主席
}

华罗庚

日从韶山出, 兾宇沐朝晖. 1893 年 12 月 26 日我们伟大领袖和导师毛泽东主席在韶山诞 生了. 半个多世纪来毛主席以他那光辉不朽的一生,把马克思列宁主义普遍真理同中国革命的 具体实践相结合,缔造了我们伟大的党,伟大的军队,伟大的社会主义新中国. 从此,灾难深重 的中华民族站立起来了,毛主席领导的中国人民革命的胜利, 改变了东方和世界的形势. 为全 世界被压迫民族和被压迫人民的解放事业，开辟了新的道路. 毛主席在各个方面继承、捍卫和 发展了马克思列宁主义, 丰富了马克思主义的理论宝库. 毛主席是人民的大救星, 虽然他老人 家与我们永别了,但毛主席为全中国和全世界革命人民立下的丰功伟绩是永存的,毛泽东思想 是照耀我们前进的灯塔,毛主席是我们心中永远不落的红太阳. 他老人家英明伟大,高瞻远瞩, 生前为我们选定了掌舵人华国锋同志. 华主席和以华主席为首的党中央继承毛主席的遗志,代 表全国人民的根本利益,英明果断一举粉碎了王张江姚“四人帮”反党集团篡党夺权的阴谋, 为 党锄奸, 为国除害, 为民平愤, 使我们无惊无恐, 兵不血刃, 安稳地渡过了急流险滩, 使历史避免 了一次大倒退,使中国人民避免了一次大灾难. 华主席是当之无愧的党和人民的领袖.毛主席 亲笔给华国锋同志写的指示: “你办事, 我放心”. 光照史册, 英明无比.我们无限怀念毛主席, 无限热爱和信赖华主席.

我是一个从旧社会过来的知识分子. 由于毛主席他老人家的多次关怀,耳提面命,才有所 觉悟,有所前进. 使我在迷雾中有了方向, 非䧃中增强了信心和力量. 在纪念我们伟大领袖和 导师毛主席诞辰 83 周年的日子里, 回顾以往, 心情激荡. 毛主席的光辉形象就在眼前, 他老人 家的谆谆教导终生难忘.

1964 年 3 月 18 日, 我在医院里的牵引床上已好几天了。幸福从天降! 我们伟大导师 毛主席亲笔给我写来了回信. 这是我一生的转折点. 虽然身子动弹不得, 但心潮翻腾, 脑子里 不断地回忆对比,正是毛主席的《七律 - 和郭沫若同志》这篇反修防修的檄文启发了我,教育了 我,使我认识了过去,才向毛主席写信汇报了我的学习体会. 毛主席日理万机,明察一切,看到 我思想上出现一些苗头, 就给了极大的鼓励. 用“壮志凌云”来鞭策我前进. 回忆起来,毛主席 以往不是没有教导过我的, 但由于我从旧社会中来, 往往用旧思想来理解毛主席的指示, 结果 辜负了他老人家的谆谆教诲.

例如, 1952 年的一次晚会上,我幸福地坐在毛主席的身边. 他老人家对我亲切地说,你也 是苦出身嘛, 希望你为我们多培养出些好学生来. 当时我十分激动, 恳切地表示, 一定努力工 作, 决不宰负毛主席的期望. 但说来惭愧, 那时错误地认为, 培养好学生就是按照我在国外所 行、所见的那样，培养一些业务尖子，完全不理解 “应该使受教育者在德育、智育、体京几方面 部制到发展，成为有社会主义觉悟的有文化的劳动者” 的大道理. 而我在教学上、科研上片面 地强调业务训练, 实际上在影响一些青年成为我那样的追求成名成家而不知道为哪个阶级服 
务的人, 我糊里糊涂辛辛苦苦地又教学又搞科研, 实际上在为修正主义教育路线服务, 科研选 题也是积重难返的旧一套. 当然我并不是说我带出来的学生全是旧我的翻版. 其中有不少人 走出校门后, 听毛主席的话, 走社会主义的路, 接受工农兵的再教育, 成为新型的知识分子. 但 我始终内疚,诚恐我的瘨疶会或隐或现地在影响他们. 这说明了旧立场是无法理解新思想的.

在建设社会主义总路线的指引下, 在大跃进的热潮中, 我曾尝试按照毛主席《在延安文艺 座谈会上的讲话》的精神, 下楼出院, 到群众中去、到生产实践中去, 尝到了甜头, 收到效果. 但 立足未稳, 路线不清, 听到一些议论就又退缩到原来的小天地中去了. 这足以说明了, 即使认 识上有些改变,但小资产阶级的摇摆性是顶不住风浪的.

在毛主席伟大诗篇的启发下, 使我们认识到其根源是 “一从大地起风雷, 便有精生白里 堆”, 旧社会正是白骨成堆的地方, 从旧社会过来的知识分子有两种前途: 一种是“妖为鬼城必 成灾”; 一种是坚决地与旧传统观念彻底决裂, 改造世界观, 站在人民群众一边, 为其所用. 毛主席 3 月 18 日的指示, 使我认识到, 虽然我不认识路, 但还是“僧是曼记犹可训” 的愚讯, 还 是一个可以改造的人. 这一巨大鼓舞和鞭策使我跳出老框框, 写了《统筹方法平话》。平话者, 平常讲话之意也. 我以往的科学文风是盲目的“深”、“高”、“难”. 世界上的“名权威”、“大学 者”欣觉赞美就欣然自得, 以为达到或超过世界先进水平了. 至于我这理论与实际有何关系, 则不管，与祖国的社会主义建设有何关系更不在意. “平话”是着眼于广大工农群众能懂能用， 着眼于生产实际能广泛地见成效. 会有这一转折, 完全归于伟大导师毛主席的教导. 写了“平 话”还需要去实践. 我们第一次下厂试点, 没有出成果, 大败而归, 检查起来原因有好几个, 但主 要是我没有亲自去实践. 不久西南工地让我去, 开始我顾虑重重, 莫知所措, 但是想到毛主席 的教导,使我想到䟗下来能叫“壮志凌云”? 于是不怕失面子, 决心放下架子, 到了施丁现场. 原 先我顾虑, 我是个单科独进, 仅对理论数学略知一二的人, 这也不懂, 那也不懂, 怎么办? 但事 实教育了我, 不但工农兵在与穷山恶水斗争中的先进事迹教育了我, 而且不以我这也不懂, 那 也不知道而看不起我, 反而教会我许多东西. 我用平话形式向师傅们介绍了《统筹方法》。开 始体会到搞教学科研也有一条“送货上门, 取宝下山” 的道路. 这时候我才第一次比较深刻地 认识到毛主席教导我们的, “群众是真正的英雄, 而我们自己则往往是幼淮可笑的”, 在西南, 时 间不算长，我仅仅向师傅们送上了《统筹方法》这一小小的工具,但自己收获不少. 开始看到在 毛泽东思想指引下, 我国自有一条发展科学技术的道路.

在我刚刚迈出这一步的时候,伟大导师毛主席又注意到了。1965 年 7 月 21 日，他老人家 又给予亲笔指示, 勉励我奋发有为, 不为个人而为人民服务, 表示十分欢迎, 并为我们能到西南 工地学习、锻炼, 与工农相结合,表示极为庆幸.

在旧社会我虽然出身苦些, 初中毕业后就上不起学了. 但先是为了养家活口, 后来为了成 名成家, 当上了洋教授, 日积月累, 受着旧社会很深的熏染, 一事当前首先考虑的是个人, 哪里 会有为人民服务的思想? “为什么人的问题, 是一个根本的问题, 原则的问题.”毛主席具体地 明确地给我们指明了前进的方向, 也是他老人家对我的殷切期望. 每当想到毛主席的这一亲 切教导, 我就添了无穷的力量, 个人考虑就少一些, 为人民服务的思想就多一些. 但还做的很 不够, 如果说我自己有了点进步的话, 都是毛主席关怀的结果.

1966 年毛主席亲自发动和领导的史无前例的无产阶级文化大革命开始了, 由于我从旧中 国来、旧思想旧习惯根深蒂固, 在运动中虽然没有身当其冲, 但也受到了极为深刻的教育. 亲 自看到了形形色色的旧传统观念的污泥浊水在被清除了, 也看到郁郁苟整新生事物在成长.简 
单一句, 无产阶级文化大革命是十分必要的, 非常及时的. 但是 “四人帮” 熍起各种反动思潮, 鼓动 “打倒一切”、“怀疑一切”, 于是毛主席给我的信也被诬䔐为是假的, 是骗来的. 就在这时 侯, 1967 年 5 月 1 日毛主席在天安门城楼接见了我, 与我亲切地握手, 高兴地说, 这是我们的数 学家华罗庚同志. 巨大的信任和深切关怀使我沉浸在无限幸福之中. 下来以后, 我更暗暗下 定决心，抖擞精神，继续革命，不断前进，正确对待文化大革命，正确对待群众，正确对待自己.

敬爱的周总理是毛主席革命路线的坚决执行者和捍卫者. 文化大革命中, 周总理废寝忘 食，日夜为国家大事操劳，坚决忠诚地贯彻执行毛主席的无产阶级革命路线和各项方针政策， 把毛主席党中央对知识分子的关怀送到每个人的心坎上, 我们永远怀念他、崇敬他. 1970 年 初, 周总理就批示, 统筹方法还是要搞的. 接着, 国务院有关部门召集各部委负责人会议, 部署 了推广统筹方法的工作. 这年夏天, 我们重新蹲点, 又开始搞起了推广应用统筹法, 同时由于 工人同志们的努力,优选法在生产中也见到了成效.

在无产阶级文化大革命的推动下,由于毛主席为首的无产阶级司令部的关怀,各地各级党 的一元化领导, 时间不长, 推广应用统筹法、优选法由点到面,逐步发展. 到 1972 年就形成了 比较广泛的群众性的科学实验运动, 出现了以工人为主体的“三结合”的推广优选法小分队,使 我大开眼界,倍受教育. 想到只有社会主义的新中国才会有这种推广数学方法的新气象, 只有 毛主席的关怀才使我投身到广大群众中去。这时我便把大连机车车辆厂“三结合”小组应用优 选法的相册呈送他老人家赐阅, 1972 年 11 月 4 日毛主席作了批示, 让我保存起来, 鼓励我永 远不忘工人阶级的关怀, 继续走与工农相结合的道路. 不久我们到了大庆, 以铁人王进喜同志 为代表的大庆工人阶级从各方面给了我极其深刻的再教育, 使我更加坚定了信心. 当时写了 四句话: “甫离白骨堆,工农迎我归, 迎我绝旧我,与旧永相违”。千真万确, 毛主席给我指引的 路越走越宽广．依靠党的领导, 依靠广大群众的智慧、干劲和创造性,优选法的应用遍及化工、 电子、冶金、轻工、纺织、机械等许多行业,这是我以往在书斋中埋头研究，脱离政治、脱离群众、 脱离实际所完全想象不到的. 工农群众是我的老师,在群众性的科学实验大舞台上,自己只有 老老实实当一个向师傅们递工具的小徒工．可是自封为“正确路线的代表”、“文化大革命的功 臣”的“四人帮”却非常仇视我们．他们在教育部门的一个黑干将不惜亲自下到群众的宿舍,宫 到医院的病房，搜集我的所谓“材料”，进行造谣中伤。大野心家江青在法家著作注释会上恶狠 狠地指名说: “华罗庚压制新生力量”打击别人, “偷”别人的数学成果. 竭尽诽谤之能事, 欲置 我于死地而后快.一时间,江青的 “讲话” 在不少地方广泛传播开来,给那里推广应用优选法、 统筹法带来很大阻力. 姚文元不仅如此, 还利用他把持的與论工具, 扣压我们的文章不许发 表,授意有关部门不报道有关推广应用优选法、统筹法的消息和经验．有些单位的文章中明明 写着优选法, 都被改为技术革新. 进而通过他们控制的一些人利用特殊的手段, 片面反映情 况, 混淆视听.

我们深知觉悟不高, 又要走前人所未走过的路, 缺乏工作经验, 工作中的缺点甚至错误是 一定会有的, 并且是不会少的. 就我个人说, 走老路驾轻就熟, 走新道一步一难, 都要摸索和尝 试. 因此,领导上及时的帮助是非常需要的.

华主席在去年四月份就曾再次地关注我们的工作，及时地作了重要指示,这是对我们的极 大关怀和爱护. 但是, 在“四害”横行的时候, 却被扣压不向我们传达, 相反铋意歪曲华主席讲 话精神, 中途解散了由十几个省市派人参加的以工人为主体的“三结合”推广优选法小分队.不 准我们执行原定去四川的计划. 后来由于领导上的关怀, 使我又有机会到西南和东北去学习, 
由于心情沉重, 有“妖雾”重来的感觉, 不幸在哈尔滨一病甚重. 这时想到毛主席的关怀和殿 切期望. 去年 “十一”向他老人家写信, 汇报了十年来的体会和曾遇到的阻力以及今后自己的 决心。毛主席已经八十以上高跉, 每天不知有多少国家大事要处理, 但他老人家又在 10 月 5 日作了批示, 进一步给指明了前进的方向. 他老人家还无微不至地关怀我的身体, 要我病愈后 多休养一段时期,好后再出去. 在病中我看着毛主席那苍动有力的笔迹, 激动得热泪盈眶. 是 毛主席把我从迷途中引上了光明, 是毛主席在我彷得中给指出了方向, 是毛主席在我学步时给 我满腔热忱的鼓励, 是毛主席给了我新的生命. 我们是多么希望他老人家健康长寿呵！不幸 今年 9 月 9 日他老人家逝世了. 哥耗传来, 使我悲痛万分. 当天下午接到人民日报的同志来 电话向我约稿. 连夜我就写了缅怀伟大领袖和导师毛主席的教导, 悼念他老人家的文章, 校样 也排好了,却被姚文元扣下不让发表。理由是“这样的文章更不能以华罗庚这样的老头名义发 表”.就这样,在“四人邦”的手里,我们歌颂毛主席悼念毛主席的权利也被剥存了.

风雷激,齐欢呼. 我们又有了自己的英明领袖华主席, “四人帮” 反党集团被一举粉碎了. 王张江姚这伙野心家、阴谋家,终究逃不脱覆灭的下场。他们丧心病㾏地迫害我们伟大领袖和 导师毛主席,恶毒攻击敬爱的周总理,反对华主席,祸国殊民，人心丧尽, 极为孤立. 他们打着 马克思主义的旗号, 搞修正主义,到处插手网罗亲信,送材料，写黑信,作黑报告,欺世盗名, 制 造分裂,搞阴谋栬计,安图篡党夺权, 罪行滔天. 他们插手科技界, 胡乱批示, 制造混乱, 破坏党 对知识分子的“团结、教育、改造”的政策，同样大搞顺我者昌，逆我者亡. “四人邦”如此干扰破 坏我们走毛主席指引的光辉道路, 是由他们的反革命本质所决定的. 他们是我们党的大敌, 工 人阶级的大敌、全中国人民的大敌，也是一切愿意革命的知识分子的大敌. 扫除“四害”，大快 人心,大振人心. 今后, 我一定在华主席为首的党中央领导下,团结更多的知识分子, 到工农群 众中去接受再教育,不为个人而为人民服务,继续努力,一息尚存,战斗不止. 